11,19

\title{
Фазовые переходы и тепловое расширение в сплавах $\mathrm{Ni}_{51-x} \mathrm{Mn}_{36+x} \mathrm{Sn}_{13}$
}

\author{
() Ю.В. Калетина ${ }^{1}$, Е.Г. Герасимов ${ }^{1,2}$, В.А. Казанцев ${ }^{1}$, А.Ю. Калетин ${ }^{1}$ \\ ${ }^{1}$ Институт фризики металлов им. М.Н. Михеева УрО РАН, \\ Екатеринбург, Россия \\ ${ }^{2}$ Уральский фредеральный университет, \\ Екатеринбург, Россия \\ E-mail: kaletina@imp.uran.ru
}

(Поступила в Редакцию 27 марта 2017 г.)

Исследованы тепловое расширение, структурные и магнитные фазовые переходы в сплавах системы $\mathrm{Ni}-\mathrm{Mn}-\mathrm{Sn}$. Установлено, что в сплавах $\mathrm{Ni}_{51-x} \mathrm{Mn}_{36+x} \mathrm{Sn}_{13}(0 \leq x \leq 3)$ спонтанное мартенситное превращение сопровождается большими скачками на температурных зависимостях линейного теплового расширения. Относительное изменение линейных размеров в этих сплавах при мартенситном превращении составляет $\sim 1.5 \cdot 10^{-3}$. На температурных зависимостях коэффициента линейного теплового расширения не наблюдается аномалий в области температур магнитного упорядочения. Установлены различия в поведении линейного теплового расширения при мартенситном превращении в сплавах $\mathrm{Ni}_{51-x} \mathrm{Mn}_{36+x} \mathrm{Sn}_{13}(0 \leq x \leq 3)$ и сплаве $\mathrm{Ni}_{47} \mathrm{Mn}_{40} \mathrm{Sn}_{13}(x=4)$.

Работа выполнена в рамках государственного задания (тема „Структура“, № 01201463331) при частичной поддержке РФФИ (проект № 16-03-00043) и проекта № 15-17-2-24 УрО РАН.

DOI: 10.21883/FTT.2017.10.44968.096

\section{1. Введение}

Трехкомпонентные сплавы системы $\mathrm{Ni}-\mathrm{Mn}-\mathrm{Sn}$ относятся к классу многофункциональных сплавов Гейслера. В этих сплавах наблюдаются эффект памяти формы, магнетокалорические свойства, сверхпроводимость, магнитооптические и другие эффекты [1-5]. Свойства таких материалов в значительной степени зависят от расположения атомов в кристаллической решетке. Расчеты зонной структуры показывают, что уже небольшое разупорядочение в распределении атомов в узлах кристаллической решетки вызывает определенные изменения в их электронной структуре, а следовательно, и в их магнитных и транспортных свойствах [4].

Среди магнитоупорядоченных сплавов Гейслера с эффектом магнитной памяти формы наиболее хорошо изучены сплавы семейства $\mathrm{Ni}-\mathrm{Mn}-\mathrm{Ga}$ [1-3]. Новые сплавы, не содержащие галлия, на основе $\mathrm{Ni}-\mathrm{Mn}-\mathrm{Z}$ $(Z=\mathrm{In}, \mathrm{Sn}, \mathrm{Sb})$ в настоящее время вызывают повышенный интерес [6-9]. В них более сложная последовательность структурных и магнитных переходов, чем в сплавах $\mathrm{Ni}-\mathrm{Mn}-\mathrm{Ga}$. Существуют широкие области концентраций, в которых наблюдаются магнитное упорядочение и мартенситные превращения [8,10-12].

Продолжается поиск составов, для которых мартенситное превращение происходит вблизи комнатной температуры, а температура Кюри аустенита остается выше температуры мартенситного превращения. Активно исследуются мартенситные превращения и магнитные свойства в сплавах типа $\mathrm{Ni}-\mathrm{Mn}-\mathrm{Z}$ [4-14]. Например, приводятся сведения о том, что для системы $\mathrm{Ni}_{0.50} \mathrm{Mn}_{0.50-x} \mathrm{Sn}_{x}$ в узком диапазоне концентраций $x=0.13-0.15$ наблюдается обратный магнетокалорический эффект, в 3 раза превышающий магнетокалорический эффект в соединениях $\mathrm{Ni}-\mathrm{Mn}-\mathrm{Ga}$ [5]. Существуют большие перспективы возможного использования и технологического применения таких материалов [8].

Целью настоящей работы является исследование структурных и магнитных фазовых переходов и теплового расширения в сплавах $\mathrm{Ni}_{51-x} \mathrm{Mn}_{36+x} \mathrm{Sn}_{13}(0 \leq x \leq 4)$.

\section{2. Методика эксперимента}

В работе изучались сплавы семейства $\mathrm{Ni}_{51-x} \mathrm{Mn}_{36+x} \mathrm{Sn}_{13}$, где $x$ изменяется от 0 до 4. Таким образом, в исследуемых сплавах атомы никеля последовательно замещаются атомами марганца при неизменном содержании олова.

Сплавы $\mathrm{Ni}_{51-x} \mathrm{Mn}_{36+x} \mathrm{Sn}_{13} \quad(0<x \leq 4)$ выплавлены методом электродуговой плавки в атмосфере аргона. После выплавки они подвергались гомогенизирующему отжигу при температуре $1123 \mathrm{~K}$ в течение $168 \mathrm{~h}$ с последующей закалкой в воде, затем вырезались образцы для структурных исследований и магнитных измерений.

Структурные исследования выполнены на оптическом микроскопе „Neophot-30“ на шлифах после травления и на сканирующем электронном микроскопе „Quanta-200“ с локальным микрорентгеноспектральным анализом, а также оборудованном системой EBSD-анализа. Использовалось оборудование отдела электронной микроскопии ЦКП „Испытательного центра нанотехнологий и перспективных материалов“ ИФМ УрО РАН.

Дилатометрические измерения выполнены на образцах размером $5 \times 5 \times 5 \mathrm{~mm}$ на дилатометре DL-1500RHP 

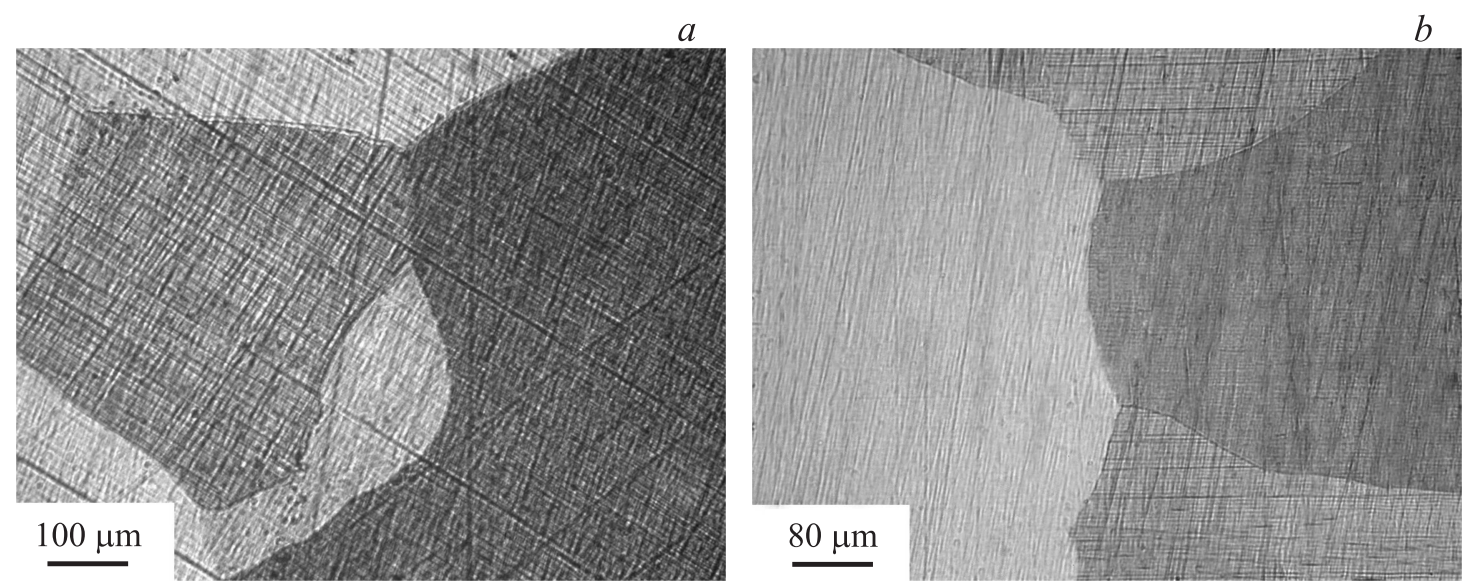

Рис. 1. Микроструктура сплавов $\mathrm{Ni}_{48} \mathrm{Mn}_{39} \mathrm{Sn}_{13}(a)$ и $\mathrm{Ni}_{47} \mathrm{Mn}_{40} \mathrm{Sn}_{13}$ (b) после отжига.

$a$

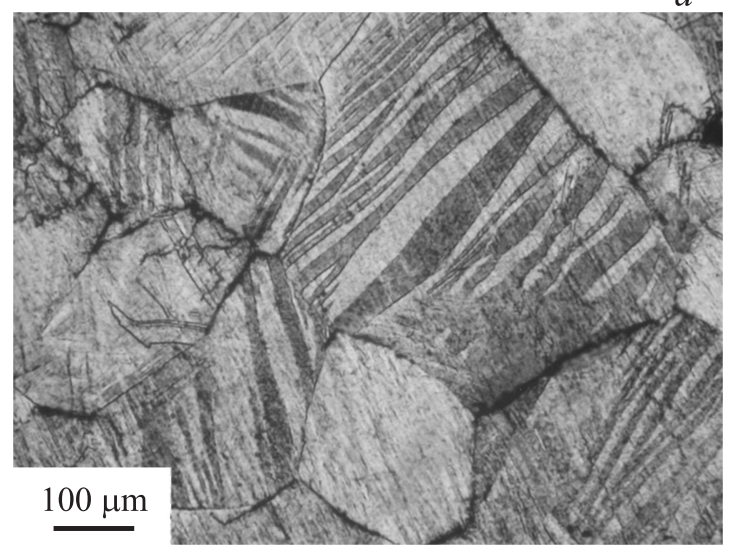

$c$

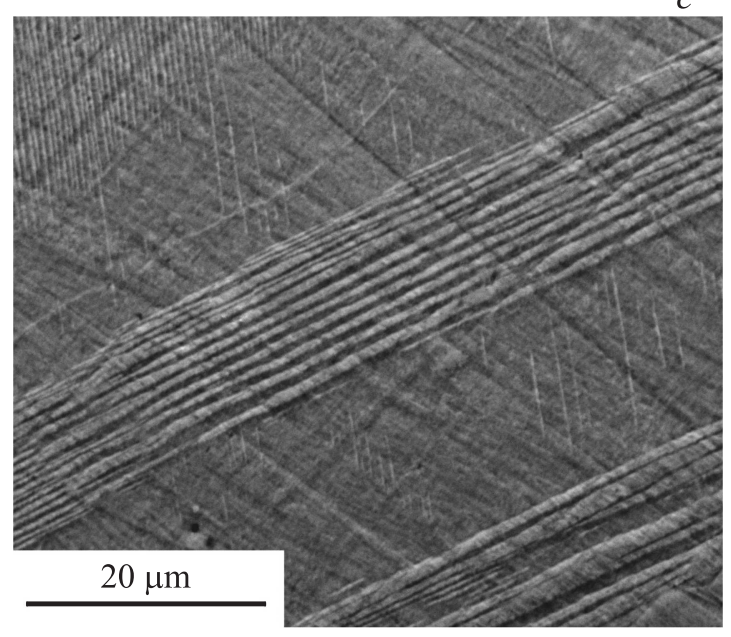

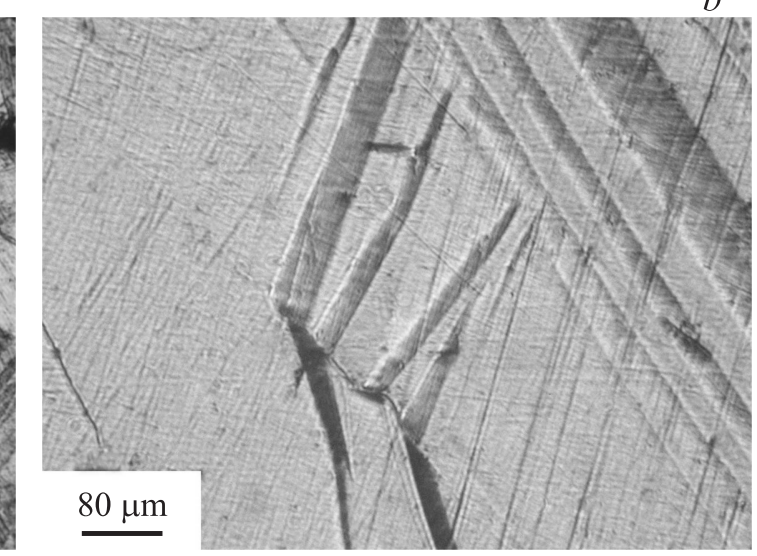

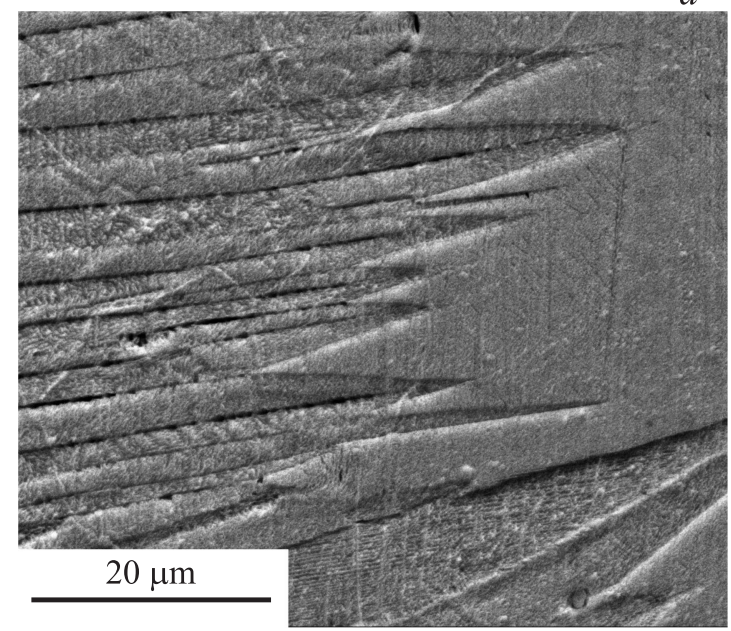

Рис. 2. Микроструктура и рельеф на полированной поверхности шлифа сплавов $\mathrm{Ni}_{51} \mathrm{Mn}_{36} \mathrm{Sn}_{13}(a, c), \mathrm{Ni}_{50} \mathrm{Mn}_{37} \mathrm{Sn}_{13}(b, d)$ после отжига.

в интервале температур от 80 до $400 \mathrm{~K}$ при скорости нагрева $2 \mathrm{~K} / \mathrm{min}$ в атмосфере гелия.

Магнитные измерения выполнены в секторе импульсных магнитных полей ИФМ УрО РАН. Измерения амплитудной магнитной восприимчивости $\chi_{\mathrm{ac}}$ проводились с использованием метода скомпенсированного трансформатора в диапазоне температур $78-350 \mathrm{~K}$ в переменном магнитном поле, синусоидально изменяющемся с частотой $80 \mathrm{~Hz}$ и амплитудой 4 Ое. 


\section{3. Результаты исследования и обсуждение}

Все исследуемые сплавы после отжига при температуре $1123 \mathrm{~K}$ имели крупнозернистую поликристаллическую структуру (рис. 1). Границы исходных зерен ровные и чистые. Сплавы $\mathrm{Ni}_{49} \mathrm{Mn}_{38} \mathrm{Sn}_{13}, \mathrm{Ni}_{48} \mathrm{Mn}_{39} \mathrm{Sn}_{13}$, $\mathrm{Ni}_{47} \mathrm{Mn}_{40} \mathrm{Sn}_{13}$ находились в однофазном состоянии при комнатной температуре. В них наблюдалась только высокотемпературная аустенитная фаза (рис. 1).

В структуре сплавов $\mathrm{Ni}_{51} \mathrm{Mn}_{36} \mathrm{Sn}_{13}$ и $\mathrm{Ni}_{50} \mathrm{Mn}_{37} \mathrm{Sn}_{13}$ кроме аустенитной фазы присутствуют кристаллы мартенсита (рис. 2). На поверхности шлифов сплавов $\mathrm{Ni}_{51} \mathrm{Mn}_{36} \mathrm{Sn}_{13}$ и $\mathrm{Ni}_{50} \mathrm{Mn}_{37} \mathrm{Sn}_{13}$ отчетливо выявляется рельеф. Мартенситный рельеф в сплаве $\mathrm{Ni}_{51} \mathrm{Mn}_{36} \mathrm{Sn}_{13}$ представляет собой полосы, сформированные из тонких мартенситных кристаллов с параллельными гранями, подобно пакету мартенсита (рис. 2,c). В соседних областях мартенситные кристаллы могут быть разориентированы относительно друг друга на определенный угол.

В сплаве $\mathrm{Ni}_{50} \mathrm{Mn}_{37} \mathrm{Sn}_{13}$ мартенситный рельеф другого вида, чем в сплаве $\mathrm{Ni}_{51} \mathrm{Mn}_{36} \mathrm{Sn}_{13}$ (рис. 2, $d$ ). Хорошо видны растущие клиновидные мартенситные кристаллы

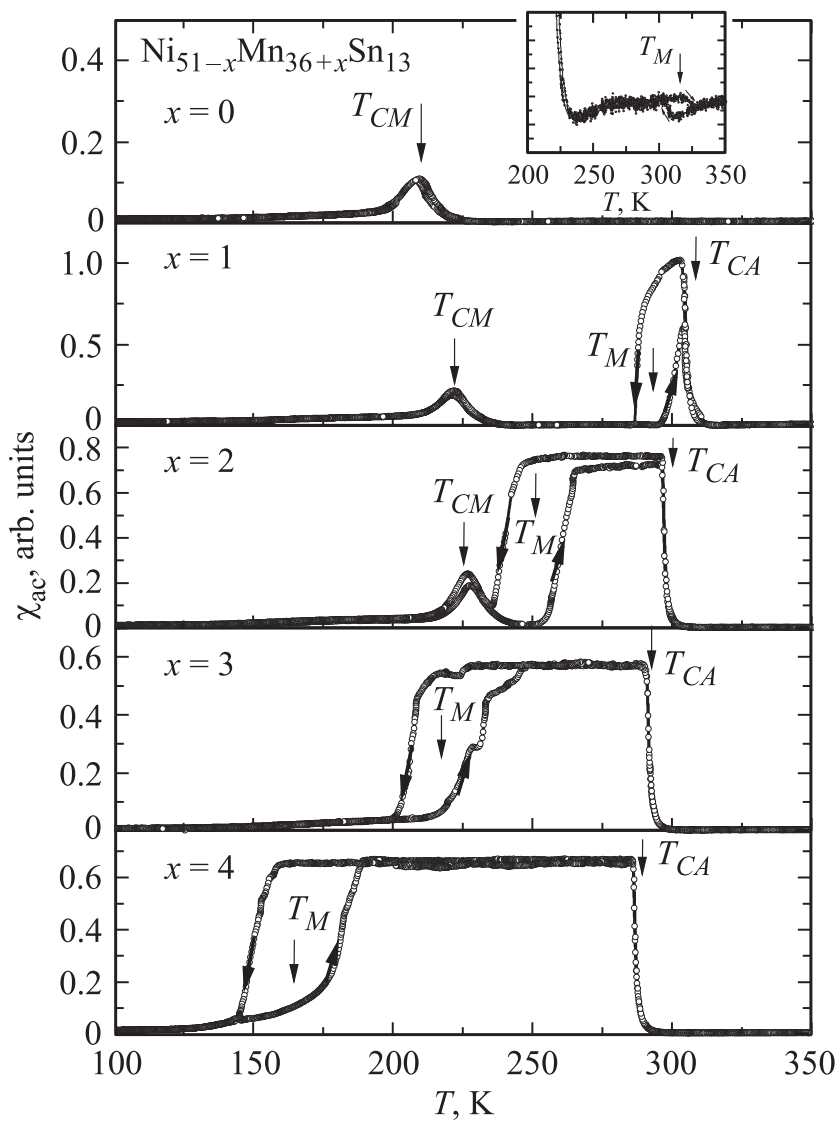

Рис. 3. Температурные зависимости амплитудной магнитной восприимчивости $\chi_{\mathrm{ac}}$ для сплавов $\mathrm{Ni}_{51-x} \mathrm{Mn}_{36+x} \mathrm{Sn}_{13}$ $(0 \leq x \leq 4)$, измеренные при нагреве и охлаждении (направление изменения температуры показано стрелками на кривых). На вставке - изменение магнитной восприимчивости сплавов в большем масштабе.

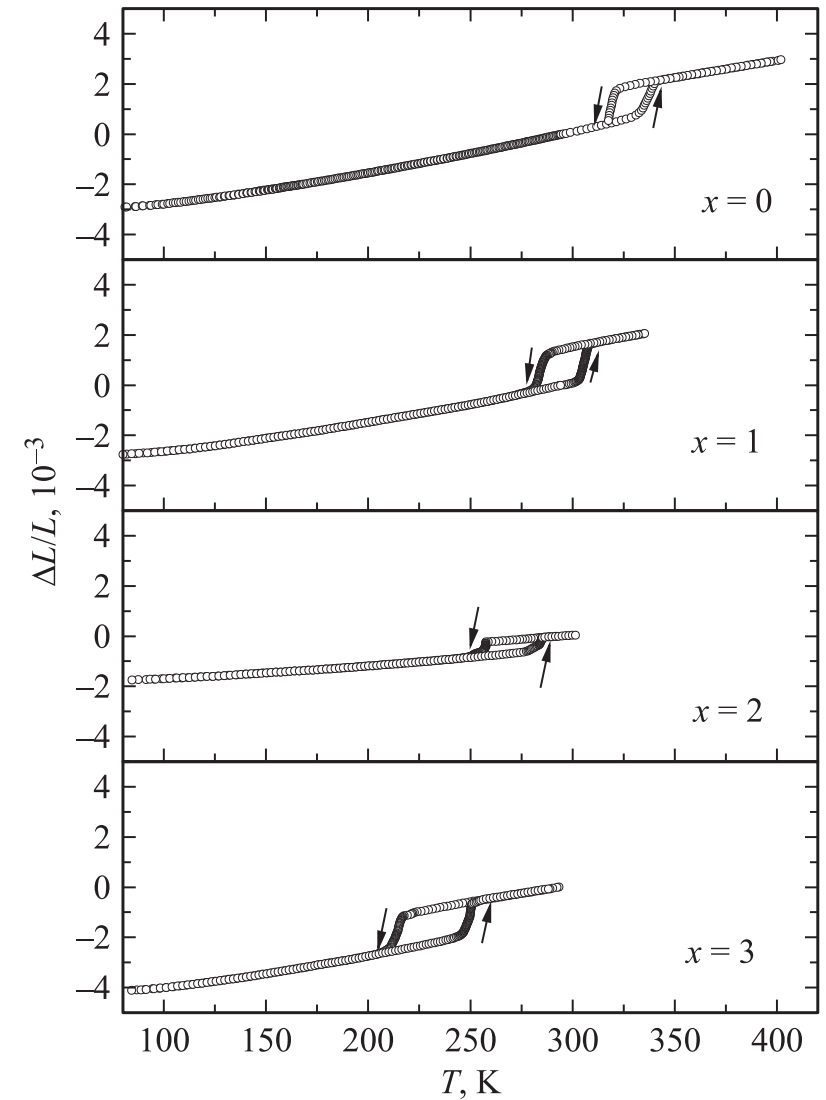

Рис. 4. Линейное тепловое расширение сплавов $\mathrm{Ni}_{51-x} \mathrm{Mn}_{36+x} \mathrm{Sn}_{13} \quad(0 \leq x \leq 3)$, измеренное при скорости изменения температуры $2 \mathrm{~K} / \mathrm{min}$.

с заостренными концами. Кристаллы имеют среднюю линию, подобную мидрибу в кристаллах мартенсита в сплавах $\mathrm{Fe}-\mathrm{Ni}[3,15]$. Интерес представляет исследование тонкой структуры мартенсита, что предполагается сделать в дальнейшем с применением методов электронной микроскопии.

На температурных зависимостях начальной магнитной восприимчивости $\chi_{\mathrm{ac}}(T)$ сплавов отчетливо видны аномалии, связанные с существованием спонтанного мартенситного превращения в сплавах при температуре $T_{M}$ и магнитных фазовых превращений при критических температурах возникновения магнитного упорядочения в мартенсите $T_{C M}$ и ферромагнитного упорядочения в аустените $T_{C A}$ (рис. 3). Как было показано нами ранее в работе [16], аустенит в сплавах имеет кубическую структуру типа $L 2_{1}$ (пространственная группа $F m 3 m$ ) с параметром решетки при комнатной температуре $a=0.5985 \mathrm{~nm}$, практически не зависящим от концентрации $x$. Кристаллическая структура мартенсита в сплавах модулированная и описывается в рамках ромбической симметрии (пространственная группа Pnnm).

На образцах всех сплавов было измерено линейное тепловое расширение $\Delta L / L$ в диапазоне температур $80-400 \mathrm{~K}$ при нагреве и охлаждении от комнатной температуры со скоростью $2 \mathrm{~K} / \mathrm{min}$. На температурных 


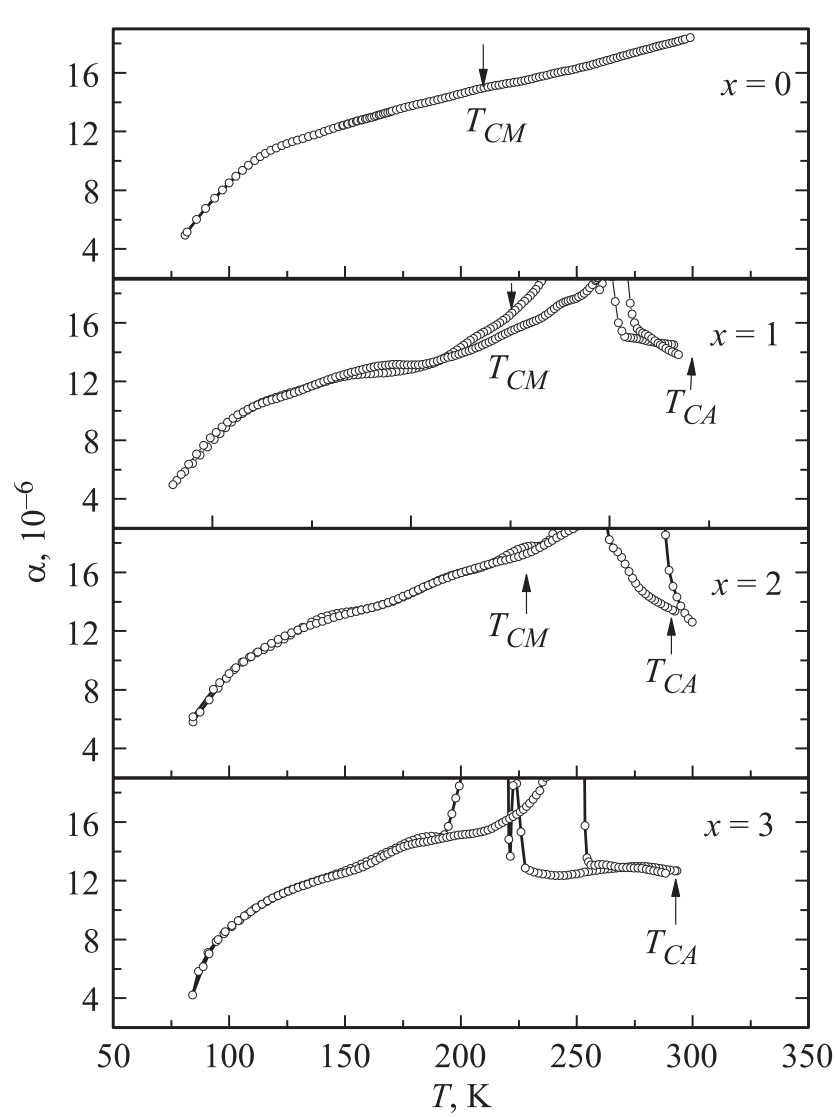

Рис. 5. Температурные зависимости коэффициента линейного теплового расширения сплавов $\mathrm{Ni}_{51-x} \mathrm{Mn}_{36+x} \mathrm{Sn}_{13}(0 \leq x \leq 3)$, показанные в интервале значений $(2-18) \cdot 10^{-6}$.

зависимостях теплового расширения $\Delta L / L(T)$ (рис. 4) для всех сплавов отчетливо видны скачки в области температур, совпадающих с температурами спонтанного мартенситного превращения $T_{M}$, наблюдающимися на температурных зависимостях $\chi_{\mathrm{ac}}(T)$ (рис. 3). Температурные границы гистерезиса спонтанного мартенситного превращения на зависимостях $\chi_{\mathrm{ac}}(T)$ и $\Delta L / L(T)$ практически совпадают. В сплавах с $0 \leq x \leq 3$ структурный фазовый переход из мартенсита в аустенит сопровождается значительным удлинением образцов, а обратный мартенситный переход - сокращением длины образцов. Абсолютные значения изменения длины образцов при прямом и обратном мартенситном превращениях практически совпадают и очень велики. Относительное изменение линейных размеров сплавов $\mathrm{Ni}_{51-x} \mathrm{Mn}_{36+x} \mathrm{Sn}_{13}$ с $x=0-3$ при мартенситном превращении составляет порядка $\Delta L / L \approx 1.5 \cdot 10^{-3}$ (или $0.15 \%$ ). В целом характер и значения относительных изменений линейных размеров образцов с $0 \leq x \leq 3$ при мартенситном превращении сравнимы с наблюдавшимися в классических сплавах Гейслера с магнитной памятью формы на основе системы $\mathrm{Ni}-\mathrm{Mn}-\mathrm{Ga}[17,18]$. Для новых сплавов Гейслера на основе сплавов системы $\mathrm{Ni}-\mathrm{Mn}-\mathrm{Sn}$ нам не удалось найти в литературе экспериментальных данных об изменении размеров при мартенситном превращении, а в сплавах $\mathrm{Ni}-\mathrm{Mn}-\mathrm{In}$ линейные размеры образца могут увеличиваться при фазовом переходе мартенсит-аустенит на $0.25 \%$ [19].

В области критических температур магнитных фазовых переходов $T_{C M}$ и $T_{C A}$ на температурных зависимостях $\Delta L / L(T)$ никаких особенностей не наблюдается. Поскольку аномалии теплового расширения при магнитных фазовых переходах обычно намного меньше по величине, чем при структурных, для их определения при магнитных переходах обычно используются измерения температурных зависимостей коэффициента теплового расширения $\alpha=(1 / L)(d L / d T)$. На рис. 5 показаны температурные зависимости коэффициента линейного теплового расширения (КТР) сплавов $\mathrm{Ni}_{51-x} \mathrm{Mn}_{36+x} \mathrm{Sn}_{13}(0 \leq x \leq 3)$ в интервале значений от $2 \cdot 10^{-6}$ до $18 \cdot 10^{-6}$. Как видно из рис. 5, КТР монотонно возрастает в мартенсите с ростом температуры, а в аустените остается практически неизменным или немного уменьшается. Значения $\alpha \approx(12-18) \cdot 10^{-6}$ оказываются близки к значениям КТР при комнатной температуре в традиционных сплавах Гейслера с магнитной памятью формы на основе $\mathrm{Ni}-\mathrm{Mn}-\mathrm{Ga}$ [18]. Никаких аномалий на температурных зависимостях $\alpha(T)$, которые можно было бы связать с существованием магнитных превращений, как и в случае зависимостей $\Delta L / L(T)$, не наблюдается. Таким образом, магнитный вклад в тепловое расширение сплавов $\mathrm{Ni}_{51-x} \mathrm{Mn}_{36+x} \mathrm{Sn}_{13}$ $(0 \leq x \leq 3)$ оказывается пренебрежимо малым, и все наблюдающиеся изменения линейных размеров связаны преимущественно с изменением кристаллической структуры и микроструктуры сплавов с изменением температуры.

В сплаве $\mathrm{Ni}_{47} \mathrm{Mn}_{40} \mathrm{Sn}_{13} \quad(x=4)$ на зависимости $\Delta L / L(T)$ также наблюдаются скачки (рис. 6), положение которых совпадает с температурами начала и конца мартенситного превращения, определенными с помощью магнитных измерений (рис. 3). Однако вид зависимости $\Delta L / L(T)$ в сплаве с $x=4$ значительно отличается от вида зависимости $\Delta L / L(T)$ в сплавах с $0 \leq x \leq 3$ (рис. 4). Во-первых, наблюдается противоположное изменение

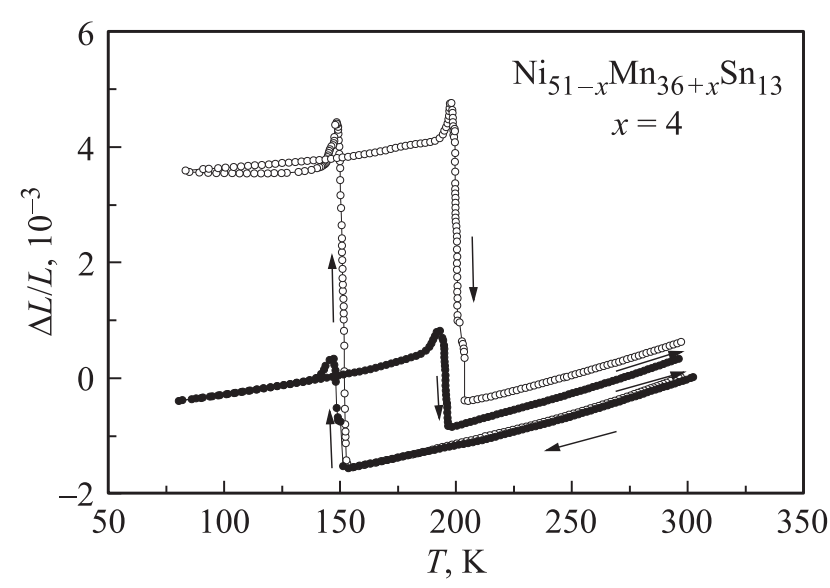

Рис. 6. Линейное тепловое расширение для двух образцов (светлые и темные символы) сплава $\mathrm{Ni}_{51-x} \mathrm{Mn}_{36+x} \mathrm{Sn}_{13}(x=4)$, измеренное при скорости изменения температуры $2 \mathrm{~K} / \mathrm{min}$. 


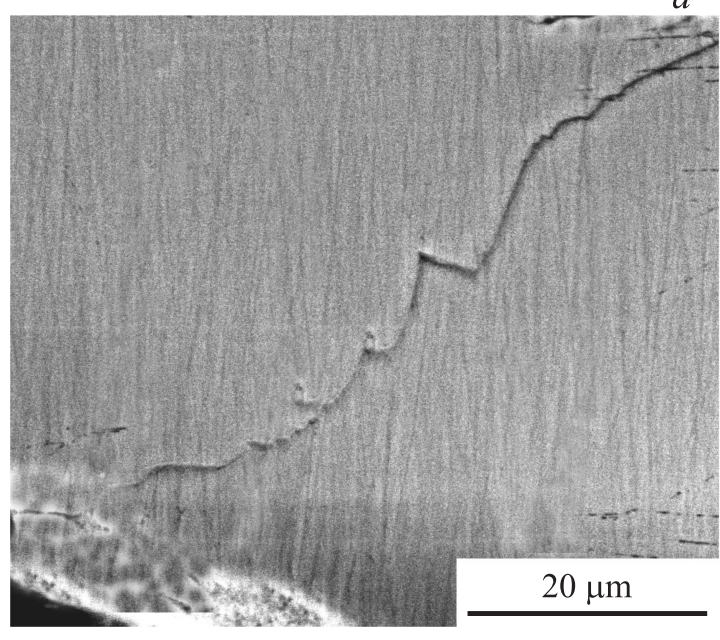

$c$

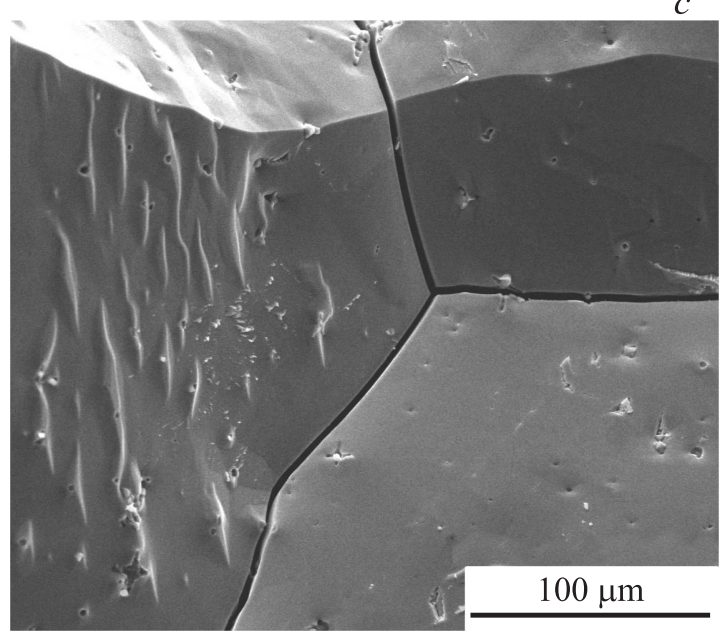

$b$

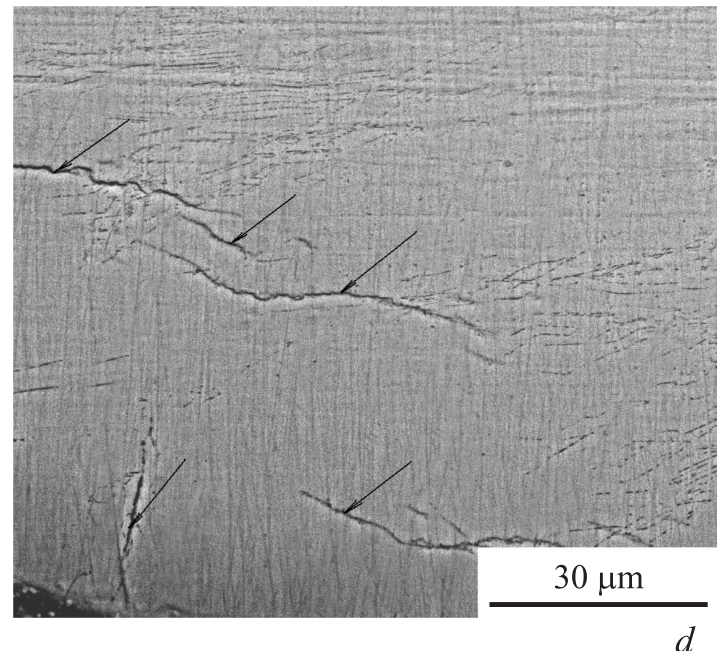

$d$

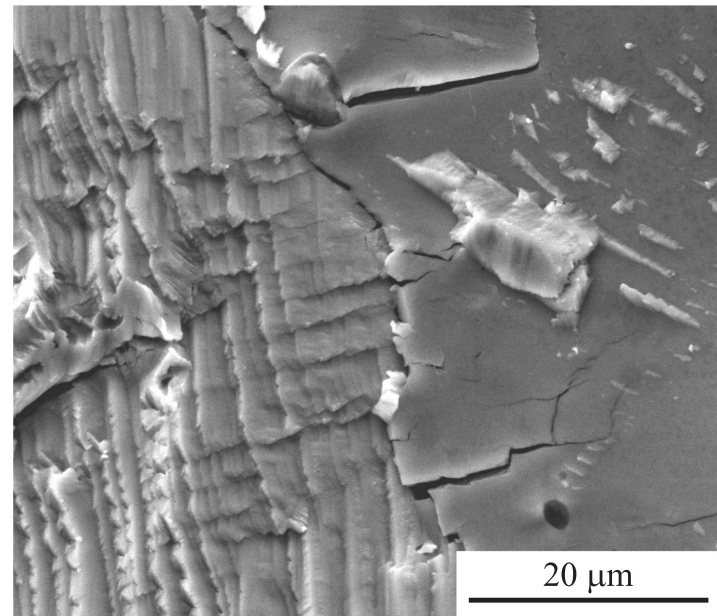

Рис. 7. Микроструктура сплава $\mathrm{Ni}_{47} \mathrm{Mn}_{40} \mathrm{Sn}_{13}$ после термоциклирования (стрелками показаны микротрещины). $a, b-$ поверхность шлифа после травления, $c, d-$ поверхность излома.

линейных размеров образца: уменьшение при переходе из мартенсита в аустенит и увеличение при обратном переходе. Во-вторых, изменение линейных размеров образца при мартенситном превращении оказывается намного больше по величине и достигает $\Delta L / L \approx 6 \cdot 10^{-3}$ (рис. 6). Как было показано в работе [17] в случае сплава $\mathrm{Ni}_{2.14} \mathrm{Mn}_{0.81} \mathrm{Fe}_{0.05} \mathrm{Ga}$, линейное изменение размеров в крупнозернистом образце при мартенситном превращении может быть анизотропным. Однако в нашем случае знак изменения линейных размеров образца сплава $\mathrm{Ni}_{47} \mathrm{Mn}_{40} \mathrm{Sn}_{13}$ повторяется при измерении $\Delta L / L(T)$ на двух образцах сплава, вырезанных из разных частей слитка, но значение скачка $\Delta L / L$ при мартенситном превращении изменяется от $2 \cdot 10^{-3}$ до $6 \cdot 10^{-3}$. Кроме того, в отличие от данных работы [17] для обоих образцов сплава $\mathrm{Ni}_{47} \mathrm{Mn}_{40} \mathrm{Sn}_{13}$ характерно необратимое изменение линейных размеров при измерении: размеры образцов после измерения не совпадают с начальными. Мы предполагаем, что существенные отличия в поведении и величине $\Delta L / L(T)$ в сплаве $\mathrm{Ni}_{47} \mathrm{Mn}_{40} \mathrm{Sn}_{13}$ от наблюдаемых для сплавов с $0 \leq x \leq 3$ могут быть связаны с формированием в сплаве $\mathrm{Ni}_{47} \mathrm{Mn}_{40} \mathrm{Sn}_{13}$ высокодефектной микроструктуры, существенно отличающейся от микроструктуры мартенсита в исследуемых сплавах с $0 \leq x \leq 3$, и больших внутренних напряжений в мартенситном состоянии. Подтверждением высказанного предположения являются проведенные нами эксперименты по термоциклированию сплавов. Циклы нагрева и охлаждения выше и ниже $T_{M}$ повторялись до 10 раз. После многократных нагревов (до $300 \mathrm{~K}$ ) и охлаждения до температуры жидкого азота в одном образце появлялись трещины (рис. 7), а второй образец рассыпался.

Трещины имеют зигзагообразную форму (рис. 7,a), при этом иногда встречаются группы параллельных трещин (рис. 7, $b, c)$. Трещины располагаются по всей поверхности образца, они идут от границ исходных зерен, а также находятся внутри тела зерна. В результате многократных циклов нагрева и охлаждения, повидимому, возникает неоднородная деформация, инициирующая первоначально появление трещин, а затем и разрушение образца. На рис. 7, $c, d$ представлен хруп- 
кий излом образца после такого разрушения. Видно, что разрушение идет по границам исходного крупного зерна аустенита и внутри зерен наблюдаются скопления микротрещин.

Таким образом, наблюдающиеся различия в характеристиках линейного расширения исследованных сплавов дают потенциальную возможность прогнозировать их механическую прочность.

\section{4. Выводы}

1. Показано, что в сплавах $\mathrm{Ni}_{51-x} \mathrm{Mn}_{36+x} \mathrm{Sn}_{13}$ $(0 \leq x \leq 3)$ спонтанное мартенситное превращение сопровождается скачкообразным относительным изменением линейных размеров образцов, достигающим $\Delta L / L \approx 1.5 \cdot 10^{-3}$ (или $0.15 \%$ ). Учитывая, что мартенситное превращение в сплавах может инициироваться магнитным полем, сплавы на основе системы $\mathrm{Ni}-\mathrm{Mn}-\mathrm{Sn}$ могут рассматриваться как потенциально перспективные высокомагнитострикционные материалы.

2. Показано, что магнитный вклад в линейное тепловое расширение сплавов $\mathrm{Ni}_{51-x} \mathrm{Mn}_{36+x} \mathrm{Sn}_{13}(0 \leq x \leq 3)$ пренебрежимо мал по сравнению с вкладами от температурных изменений параметров кристаллической структуры и микроструктуры. На температурных зависимостях линейного теплового расширения и температурного коэффициента линейного теплового расширения не наблюдается никаких аномалий в области критических температур возникновения магнитного упорядочения.

3. Установлено существование различий в поведении линейного теплового расширения при мартенситном превращении в сплавах $\mathrm{Ni}_{51-x} \mathrm{Mn}_{36+x} \mathrm{Sn}_{13}(0 \leq x \leq 3)$ и $\mathrm{Ni}_{47} \mathrm{Mn}_{40} \mathrm{Sn}_{13}(x=4)$. На основе проведенного анализа предполагается, что обнаруженные различия связаны с формированием в сплаве $\mathrm{Ni}_{47} \mathrm{Mn}_{40} \mathrm{Sn}_{13}$ при низкой температуре высокодефектной структуры с большими внутренними напряжениями.

\section{Список литературы}

[1] А.Н. Васильев, В.Д. Бучельников, Т. Такаги, В.В. Ховайло, Э.И. Эстрин. УФН 173, 577 (2003).

[2] В.Д. Бучельников, А.Н. Васильев, В.В. Коледов, В.В. Ховайло, С.В. Таскаев, В.Г. Шавров. УФН 176, 900 (2006).

[3] В.М. Счастливцев, Ю.В. Калетина, Е.А. Фокина. Мартенситное превращение в магнитном поле. УрО РАН, Екатеринбург (2007). 322 с.

[4] T. Graf, C. Felse, S.S.P. Parkin. Prog. Solid State Chem. 39, 1 (2011).

[5] T. Krenke, E. Duman, M. Acet, E.F. Wassermann, X. Moya, L. Mañosa, A. Planes. Nature Mater. 4, 450 (2005).

[6] Y. Sutou, Y. Imano, N. Koeda, T. Omori, R. Kainuma, K. Ishida, K. Oikawa. Appl. Phys. Lett. 85, 4358 (2004).

[7] T. Krenke, M. Acet, E.F. Wassermann, X. Moya, L. Mañosa, A. Planes. Phys. Rev. B 72, 014412 (2005).

[8] V.D. Buchelnikov, V.V. Sokolovskiy. Phys. Met. Metallogr. 112, 633 (2011).
[9] И.И. Мусабиров, И.М. Сафаров, М.И. Нагимов, И.З. Шарипов, В.В. Коледов, А.В. Маширов, А.И. Рудской, Р.Р. Мулюков. ФТТ 58, 1552 (2016).

[10] Ю.В. Калетина, В.М. Счастливцев, А.В. Королев, Е.А. Фокина. ФММ 113, 1086 (2012).

[11] Ю.В. Калетина, Е.Г. Герасимов, В.М. Счастливцев, Е.А. Фокина, П.Б. Терентьев. ФММ 114, 911 (2013).

[12] Ю.В. Калетина, Е.Г. Герасимов. ФТТ 56, 1583 (2014).

[13] T. Krenke, M. Acet, E.F. Wassermann, X. Moya, L. Manosa, A. Planes. Phys. Rev. B 73, 174413 (2006).

[14] K. Koyama, K. Watanabe, T. Kanomata, R. Kainuma, K. Oikawa, K. Ishida. Appl. Phys. Lett. 88, 132505 (2006).

[15] Ю.В. Калетина. Металловедение и терм. обраб. металлов 9, 10 (2008)

[16] Ю.В. Калетина, Е.Г. Герасимов, В.М. Счастливцев, В.С. Гавико, П.Б. Терентьев. ФТТ 57, 361 (2015).

[17] Р.Н. Имашев, В.В. Коледов, Х.Я. Мулюков, И.З. Шарипов, В.Г. Шавров. ФТТ 47, 1867 (2005).

[18] T. Sakon, Y. Adachi, T. Kanomata. Metals 3, 202 (2013).

[19] B. Li, W.J. Ren, Q. Zhang, X.K. Lv, X.G. Liu, H. Meng, J. Li, D. Li, Z.D. Zhang. Appl. Phys. Lett. 95, 172506 (2009). 